\title{
Espectroscopia de Absorção no Ultravioleta e Visível
}

\section{J. M. G. MARTINHO*}

\section{INTRODUÇÃO}

A absorção de radiação electromagnética da região do ultravioleta (UV) $(100-400 \mathrm{~nm})$ e visivel (Vis) $(400-800$ $\mathrm{nm}$ ) por parte de moléculas, átomos ou iões está normalmente associada a transições electrónicas. Estas ocorrem quando, por interacção da radiação electromagnética com o meio absorvente, um electrão é promovido dum estado electrónico de baixa energia para outro de energia mais elevada.

A quantidade de luz absorvida quando um feixe de radiação monocromática atravessa 0 meio absorvente depende da concentração, do coeficiente de absorção molar da espécie absorvente e do percurso óptico da radiação [1]. 0 estudo da sua variação com a concentração permite: i) a determinação quantitativa de um grande número de substâncias químicas e biológicas (a título de exemplo, refira-se que mais de 95\% das análises clínicas nos Estados Unidos são feitas por métodos espectrofotométricos); ii) o estudo cinético de reaç̧ões lentas em solução; iii) a determinação de curvas de titulação. Por outro lado, a compilação de espectros de absorção (representação gráfica do coeficiente de absorção molar em função do comprimento de onda) sob a forma de atlas ou bases de dados é usada para: i) identificação e verificação do grau de pureza de compostos; ii) cálculo da diferença de energia entre estados electrónicos e do momento dipolar da transição.

0 desenvolvimento da espectroscopia de absorção UV-Vis tem sido constante ao longo dos últimos anos, sendo a técnica revista em número especial do Analytical Chemistry, de dois em dois anos, desde 1945 [2].

Este trabalho descreve os principios da espectroscopia de absorção UVVis, pretendendo constituir um conjunto de conhecimentos básicos necessários a um estudo mais aprofundado da mesma.

\section{LEI DE BEER}

A intensidade de um feixe de radiação electromagnética é atenuada ao

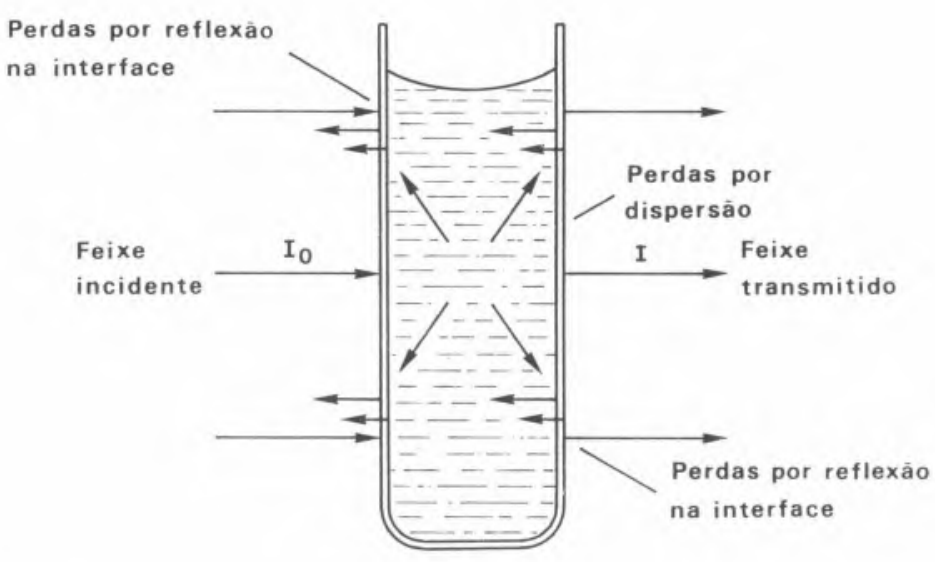

Fig. 1. Esquema dos processos que ocorrem quando um feixe de radiação electromagnética incide numa célula que contém uma solução absorvente.

atravessar um meio que contém uma espécie absorvente (fig. 1), devido a sucessivos processos de absorção, reflexões nas paredes da célula e a fenómenos de dispersão [3a].

Considerando apenas os processos de absorção, a intensidade ${ }^{1}$ do feixe transmitido, I, relaciona-se com a do feixe incidente, $I_{0}$ (paralelo e monocromático de comprimento de onda $\lambda$ ), pela lei de Beer [3]

$I=I_{0} 10^{-\varepsilon(\lambda) c b}$

onde $\mathrm{c}\left(\mathrm{mol} \mathrm{l}^{-1}\right)$ é a concentração da espécie absorvente, $\varepsilon\left(1 \mathrm{~mol}^{-1} \mathrm{~cm}^{-1}\right) 0$ coeficiente de absorção molar ao comprimento de onda $\lambda$, e b $(\mathrm{cm})$ o percurso óptico da radiação no meio ${ }^{2}$. Experimentalmente, mede-se a razão de intensidades

$T=\frac{\mathrm{I}}{\mathrm{I}_{0}}=10^{-\varepsilon(\lambda) \mathrm{cb}}$

que se designa por transmitância. Para um meio totalmente absorvente a transmitância é nula $(\mathrm{l}=0)$, enquanto que para um meio completamente transparente é unitária $\left(\mathrm{I}=\mathrm{I}_{0}\right)$. Embora a transmitância seja uma grandeza cujo significado é intuitivo, é vulgarmente substituída pela absorvência

$A=-\log _{10} T=\varepsilon(\lambda) c b$ que apresenta a vantagem de variar linearmente com a concentração, percurso óptico e coeficiente de absorção molar.

\section{DESVIOS À LEI DE BEER}

A lei de Beer é vulgarmente usada para a determinação de concentrações, coeficientes de absorção molar e mesmo percursos ópticos. A obtenção de valores exactos destas grandezas deve ter em conta os desvios à linearidade da absorvência com a concentração. Estes desvios ocorrem para concentrações superiores a $0.01 \mathrm{M}$ e resultam da variação do coeficiente de absorção molar, provocada pelas interacções entre núvens electrónicas. A esta concentração, a distância média entre espécies absorventes é próxima de 70 Å, 0 que faria supor a inexistência de interacção entre núvens electrónicas. Contudo, devido à existênciade uma distribuição de distâncias, os desvios à lei de Beer resultam de interacções entre pares de moléculas a menores distâncias. Em soluções de electrólitos este efeito é ainda mais pronunciado, podendo fazer-se sentir para concentrações muito inferiores. Uma outra causa de desvios à lei de Beer é a variação do coeficiente de absorção molar com o índice de refracção do meio que, por sua vez, depende da concentração da espécie absorvente. Os desvios à lei de Beer provocados por esta dependência não são perceptiveis para concentrações inferiores a $0.01 \mathrm{M}$, sendo geralmente ignorados. Outros 
desvios provocados por limitações instrumentais serão abordados na parte referente à instrumentação.

\section{ESPECTROS ELECTRÓNICOS}

Os espectros de absorção no UVVis de gases monoatómicos a baixa pressão são espectros de riscas, enquanto os espectros moleculares são espectros de bandas. Tal resulta do facto de as moléculas possuirem, para além da energia electrónica, energia vibracional e rotacional, enquanto os átomos apenas possuem energia electrónica. 0 diagrama energético de uma molécula no estado gasoso é bastante mais complexo do que 0 de um átomo (fig. 2), pois cada estado electrónico molecular tem associados vários estados vibracionais e rotacionais.

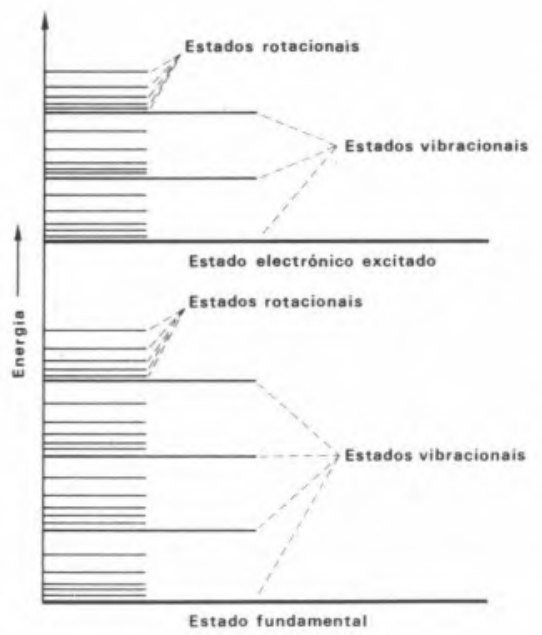

Figura 2. Diagrama esquemático dos diferentes niveis energéticos de uma molécula.

Uma transição electrónica ocorre quando a energia da radiação iguala a diferença de energia entre os estados envolvidos na transição, $\Delta \mathrm{E}$, pelo que

$\Delta \mathrm{E}=\mathrm{hc} / \lambda$

onde h é a constante de Planck, $c$ a velocidade da luz no vácuo e $\lambda$ o comprimento de onda da radiação incidente. As transições moleculares ocorrem, à temperatura ambiente, do primeiro nível vibracional do estado electrónico fundamental para vários níveis rotovibracionais dos diferentes estados excitados. Como a diferença de energia entre os niveis rotovibracionais dos estados exci- tados é muito inferior à diferença de energia entre os estados electrónicos (a diferença de energia entre níveis rotacionais é da ordem de $10 \mathrm{~cm}^{-1}<>0.13$ $\mathrm{kJmol}^{-1}$ ), a banda de absorção correspondente a uma transição electrónica é composta de um "quase contínuo" de transições. Em solução, as diferenças energia entre estados rotovibracionais são ainda menores do que as observadas no estado gasoso, devido às interacções soluto-solvente.

A intensidade de absorção, medida pelo maior ou menor valor de $\varepsilon$, depende da secção recta de captura de um fotão pela espécie absorvente, isto é, da probabilidade da transição electrónica que é ditada pelo valor do momento dipolar de transição. Transições com valores de $\varepsilon>10^{4} \mathrm{~mol}^{-1} \mathrm{~cm}^{-1}$ são francamente permitidas, enquanto valores de $\varepsilon$ $<10^{3} \mathrm{Imol}^{-1} \mathrm{~cm}^{-1}$ indicam transições proibidas [4].

\subsection{Transições electrónicas do grupo carbonilo}

Uma vez que a absorção de radiação UV-Vis por uma espécie absorvente conduz à promoção de um electrão de uma orbital para outra de maior energia, as transições electrónicas podem ser qualitativamente previstas a partir do diagrama de orbitais moleculares. 0 espectro de absorção de moléculas complexas pode, em geral, ser interpretado com base nos espectros dos seus grupos cromóforos, desde que estes estejam separados pelo menos por uma ligação simples. A título de exemplo, apresenta-se na fig. 3 o diagrama de orbitais moleculares de um cromóforo característico, o grupo carbonilo $(>\mathrm{C}=0)[4,5]$.

Figura 3. Diagrama esquemático da formaçã̃o de orbitais moleculares para 0 grupo carbonilo.
0 carbono forma uma ligação dupla (uma de tipo $\sigma$ e outra de tipo $\pi$ ) com 0 oxigénio. A ligação $\sigma$ é assegurada por dois electrões (um do átomo de carbono e outro do átomo de oxigénio) que vão ocupar uma orbital molecular ligante (de mais baixa energia do que as correspondentes orbitais atómicas), resultante da coalescência directa das orbitais atómicas híbridas $\mathrm{sp}_{2}$. A ligação $\pi$ é assegurada por dois electrões numa orbital molecular ligante, resultante da coalescência lateral das orbitais atómicas $2 p_{2}$ dos átomos de carbono e oxigénio. Os dois pares de electrões em orbitais $\mathrm{sp}_{2}$ do átomo de oxigénio não participam na ligação, pelo que ocupam orbitais moleculares não ligantes, $\mathbf{n}$, com energia semelhante à das correspondentes orbitais atómicas. 0 diagrama de niveis de energia, que inclui as orbitais antiligantes $\sigma^{\star}$ e $\pi^{\star}$ (de maior energia do que as correspondentes orbitais atómicas, pelo que não participam na ligação), mostra que a transição de menor energia corresponde à passagem dum electrão da orbital $\mathbf{n}$ para a orbital $\pi^{*}$ (transição $\mathbf{n} \rightarrow \pi^{*}$ ).

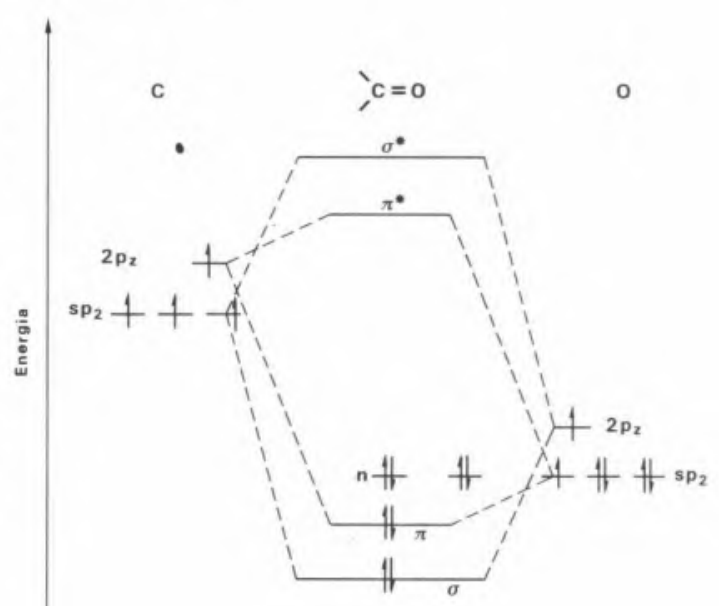

Figura 4. Diagrama de niveis de energia das orbitais moleculares do grupo carbonilo.

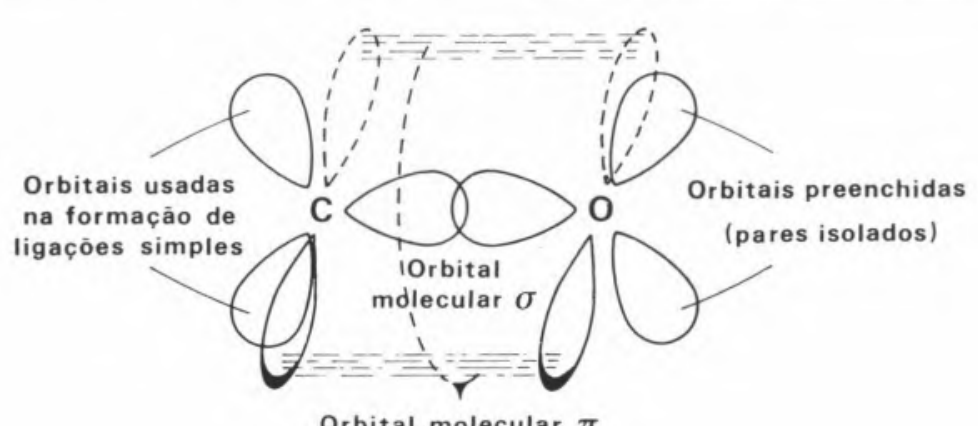

Orbital molecular $\pi$ 
Tabela I

Caracteristicas ópticas de alguns grupos cromóforos presentes $\mathrm{cm}$ moléculas orgânicas e biológicas

\begin{tabular}{|c|c|c|c|c|c|}
\hline Croméforo & Exemplo & Solvente & $\lambda_{\max } / \mathrm{nm}$ & $\varepsilon_{\max } 1 \mathrm{~mol}^{-1} \mathrm{~cm}^{-1}$ & Transiç̃ò \\
\hline Akeno & $\mathrm{C}_{8} \mathrm{H}_{8} \mathrm{OH}=\mathrm{OH}_{2}$ & n-Heptano & 177 & 13000 & $\pi \rightarrow \pi^{*}$ \\
\hline Alkino & $\mathrm{C}_{\mathrm{H}_{1}} \mathrm{C}=\mathrm{C}-\mathrm{CH}_{3}$ & n-Heptano & $\begin{array}{l}178 \\
196 \\
225\end{array}$ & $\begin{array}{c}10000 \\
2000 \\
160\end{array}$ & $\begin{array}{c}\pi \rightarrow \pi^{*} \\
- \\
-\end{array}$ \\
\hline Carbonilo & $\begin{array}{l}\prod_{\mathrm{CH}_{3} \mathrm{CCH}_{3}} \\
\prod_{\mathrm{CH}_{3} \mathrm{CH}}\end{array}$ & n-Hexano & $\begin{array}{l}186 \\
280 \\
180 \\
293\end{array}$ & $\begin{array}{c}1000 \\
16 \\
<1000 \\
12\end{array}$ & $\begin{array}{l}n \rightarrow 0^{*} \\
n \rightarrow \pi^{*} \\
n \rightarrow 0^{*} \\
n \rightarrow \pi^{*}\end{array}$ \\
\hline Cartoxilo & $\prod_{\mathrm{CH}_{3} \mathrm{COH}}$ & Etanol & 204 & 41 & $n \rightarrow \pi^{*}$ \\
\hline Amida & $\prod_{\mathrm{CH}_{3} \mathrm{CNH} / 2}$ & Água & 214 & 60 & $n \rightarrow x^{*}$ \\
\hline$A z 0$ & $\mathrm{CH}_{3} \mathrm{~N}=\mathrm{NCH}_{3}$ & Etanol & 339 & 5 & $n \rightarrow \pi^{n}$ \\
\hline Nitro & $\mathrm{CH}_{3} \mathrm{NO}_{2}$ & Iseoctano & 280 & 22 & $n \rightarrow \pi^{*}$ \\
\hline Nitroso & $\mathrm{C}_{4} \mathrm{H}_{9} \mathrm{NO}$ & Eter etilico & $\begin{array}{l}300 \\
665\end{array}$ & $\begin{array}{l}100 \\
20\end{array}$ & $\sum_{n \rightarrow \pi^{*}}$ \\
\hline Nitrato & $\mathrm{C}_{2} \mathrm{H}_{\mathrm{ONO}}$ & Dioxano & 270 & 12 & $n \rightarrow \pi^{*}$ \\
\hline
\end{tabular}

Tabela I

Características ópticas de alguns grupos cromóforos presentes em moléculas orgânicas e biológicas

Esta transição ocorre no ultravioleta $(\lambda \approx 270 \mathrm{~nm})$, sendo 0 valor exacto da sua energia dependente do solvente (efeito solvatocrómico). Solventes polares estabilizam mais as orbitais não ligantes $\mathbf{n}$ do que as orbitais antiligantes $\pi^{\star}$, provocando 0 deslocamento das bandas para maiores energias (deslocamento para 0 azul). Este tipo de transição é também responsável pela absorção no UV de aniõ̃es inorgânicos (nitrato, nitrito, etc.), com relevância em Química Analítica Alimentar [6]. Outras transi-ções, associadas à promoção de um electrão da orbital ligante para a orbital antiligante $\pi^{\star}$ (transição $\pi \rightarrow$ $\pi^{*}$ ), ou à promoção de um electrão da orbital $\mathbf{n}$ para a orbital $\sigma^{*}$ (transição $\mathbf{n} \rightarrow$ $\left.\sigma^{*}\right)$, ocorrem neste tipo de cromóforos a comprimentos de onda muito baixos (energias muito elevadas), pelo que não são experimentalmente acessíveis com os espectrofotómetros convencionais.

\subsection{Compostos com transições $\pi \rightarrow \pi^{*}$ e $n \rightarrow \sigma^{*}$ no UV-Vis}

As transições $\pi \rightarrow \pi^{*}$ podem ocorrer no ultravioleta e visivel, desde que exista deslocalização dos electrões $\pi$, como sucede, por exemplo, nos compostos aromáticos. Existem compostos orgânicos, nomeadamente corantes, com bandas de absorção $\pi \rightarrow \pi^{*}$ cobrindo toda a região do visivel até ao infravermelho próximo. As transições $\pi \rightarrow \pi^{\star}$ distinguem-se das transições $n \rightarrow \pi^{\star}$ por responderem de modo diferente à polaridade do solvente. Em geral, solventes polares estabilizam mais a orbital $\pi^{*}$ do que a orbital $\pi$, observando--se um desvio da banda $\pi \rightarrow \pi^{*}$ para menores energias (deslocamento para 0 vermelho) com 0 aumento da polaridade do solvente. Transições $n \rightarrow \sigma^{*}$ só ocorrem no ultravioleta para um número muito reduzido de compostos $\left(\lambda_{\max }=\right.$ $227 \mathrm{~nm}, \varepsilon \sim 900 \mathrm{Imol}^{-1} \mathrm{~cm}^{-1}$ para 0 $\left(\mathrm{CH}_{3}\right)_{3} \mathrm{~N} ; \lambda_{\max }=215 \mathrm{~nm}, \varepsilon \sim 600$ Imol-1 $\mathrm{cm}^{-1}$ para $0 \mathrm{CH}_{3} \mathrm{~N}_{2}$ ) [1]. Estas transições respondem à polaridade do solvente do mesmo modo que as transições $n \rightarrow \pi^{*}$, pelo que são difíceis de distinguir destas por estudos solvatocrómicos.

$\mathrm{Na}$ tabela 1 resumem-se algumas propriedades de grupos cromofóros característicos (grupo carbonilo, carboxilo, nitroso, etc.) que permitem interpretar 0 espectro de absorção de muitas substâncias.

\subsection{Absorção de complexos metálicos}

Na região UV-Vis, e mesmo no infravermelho próximo, absorvem também muitos complexos metálicos [7]. Os espectros de absorção dos complexos de lantanídeos e actinídeos são constituídos por bandas muito estreitas, características dos elementos centrais, sendo pouco afectadas pelo tipo de ligando e solvente. Tal resulta do facto de as transições electrónicas envolverem electrões em subcamadas internas, que se encontram protegidos pelos electrões das camadas electrónicas exteriores. Por seu lado, os complexos dos metais de transição apresentam espectros de bandas mais largas, que são fortemente afectadas pelo tipo de ligando, estrutura do complexo e solvente. 0 espectro de absorção UV-Vis de complexos metálicos com um grupo doador e outro aceitante de electrões pode também apresentar bandas de transferência de carga, resultantes da transferência de um electrão do grupo doador para 0 grupo aceitante. Um exemplo típico é a banda de absorção do complexo de $\mathrm{Fe}$ (III) com 0 ião tiocianato $\left(\mathrm{SCN}^{-}\right)$,
$\left[\mathrm{FeSCN}\left(\mathrm{H}_{2} \mathrm{O}\right)_{5}\right]^{2+}$ (tiocianopentaaquoferro (III)), que resulta da transferência de um electrão do ião tiocianato para 0 ião férri$c 0$, que é reduzido a ião ferroso. A espécie electronicamente excitada relaxa rapidamente para 0 estado fundamental, regenerando o complexo inicial.

\section{INSTRUMENTAÇÃO}

\subsection{Espectrofotómetros convencionais}

Os equipamentos de medida de absorvência (ou transmitância) designam-se por espectrofotómetros ou por fotómetros, conforme tenham ou não possibilidade de fazer o varrimento de comprimentos de onda (obtenção do espectro de absorção). Um fotómetro (espectrofotómetro) de absorção é basicamente constituído por uma fonte de radiação contínua, um selector de comprimentos de onda (filtros ou monocromador), o porta-amostras, um detector de radiação (fotomultiplicador, bateria de fotodíodos) e um medidor de corrente. A fig. 5 mostra as configurações básicas para fotómetros de feixe simples e de feixe duplo.

Nos equipamentos de feixe duplo mede-se directamente a absorvência (transmitância), enquanto nos de feixe simples realizam-se medidas sequenciais da intensidade do feixe incidente (usando uma célula com 0 solvente) e do feixe transmitido (usando uma célula com a amostra). Os

Figura 5. Esquema de blocos de um fotómetro de feixe simples (a) e feixe duplo (b).

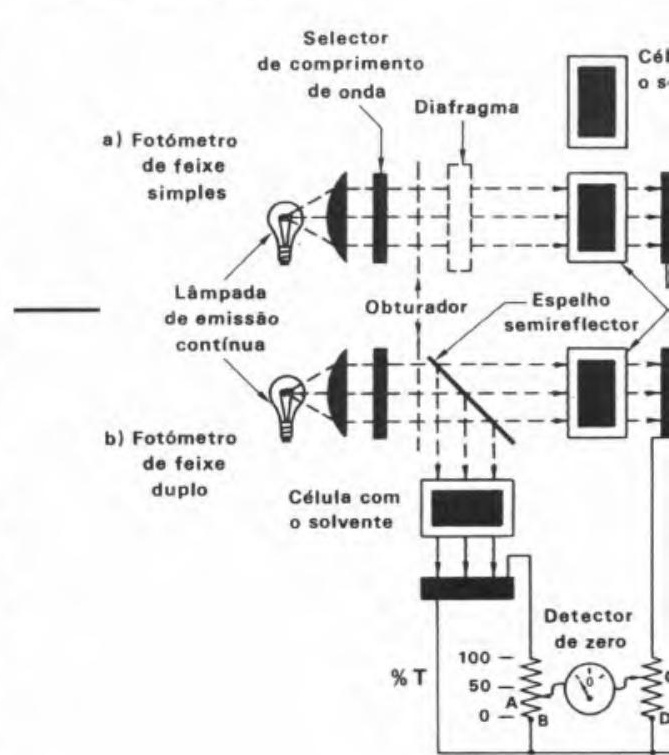




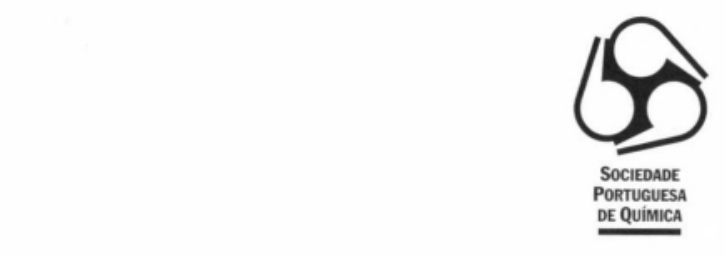

\section{Ficha Bibliográfica (Teses de Doutoramento e Mestrado)}

Autor (1)

Título

Subtítulo

Impressora (2)

Local de Impressão

Ano

$N^{\circ}$ de páginas (3)

Dimensões (em milímetros, A4 ou A5)

Área científica (4)

Localização (5)

Tese de (6)

Faculdade e Universidade

(1) Nome tal como figura na obra. (2) Se aplicável. (3) Se houver n páginas iniciais numeradas em romano indicar sob a forma $n+m$, sendo $m$ o número de páginas restantes. (4) Use palavras-chave para descrever o âmbito da obra. (5) Biblioteca (ou pessoa) que possui a obra em causa. (6) Doutoramento ou Mestrado. Para teses mais antigas transcrever as palavras originais (Dissertação para ...).

Depois de preenchida, enviar para:

Sociedade Portuguesa de Química Secretário Geral

Av. da República, 37, $4^{\circ}$

1000 Lisboa 


\title{
Ficha Bibliográfica (Livros e Sebentas)
}

Autores (1)

Título da Obra

Subtítulo

$\mathrm{N}^{\circ}$ da Edição (2)

Editora (3)

Sede da Editora (4)

Impressora (3)

Local de Impressão

Ano

Distribuidora (5)

$\mathrm{N}^{\circ}$ de páginas

Preço (6)

Dimensões (em milimetros, A4 ou A5)

Área científica (7)

Título da Série (8)

Volume $\mathrm{n}^{\circ}(8)$

Localização (9)

Notas (10)

(1) Nomes tal como figuram na obra. (2) Preencher uma ficha por cada edição da obra. (3) Nome completo. (4) Localidade. (5) Se conhecida e diferente da editora. (6) Se conhecido. (7) Use palavras-chave para descrever o âmbito da obra. (8) Se aplicável. (9) Biblioteca (ou pessoa) que possui a obra em causa. (10) Outras informações consideradas de interesse. Exemplos: tiragem da edição, tradutor (se aplicável), etc..

Depois de preenchida, enviar para:

\author{
Sociedade Portuguesa de Química \\ Secretário Geral \\ Av. da República, $37,4^{\circ}$ \\ 1000 Lisboa
}


equipamentos de feixe duplo utilizam dois feixes de luz, um que passa numa célula com a amostra e outro numa célula com o solvente, sendo os dois sinais tratados electronicamente, de modo a obter directamente a absorvência (transmitância).

Os fotómetros são muito mais baratos do que os espectrofotómetros, mas não permitem a obtenção de espectros. Contudo, a relação sinal-ruído é, em geral, boa, devido ao uso de filtros de banda larga, sendo mesmo possível usar fontes de radiação de fraca intensidade (lâmpadas de filamento de tungsténio), bem como detectores e circuitos de medida baratos.

De entre os espectrofotómetros, merece realce 0 "velho" Spectronic 20, cujo lançamento remonta aos anos 50 , e que ainda hoje, numa versão melhorada, tem grande popularidade no ensino e na indústria. Este espectrofotómetro de feixe simples usa uma lâmpada de filamento de tungsténio (340-2500nm) e um fotomultiplicador sensivel na gama de $340-625 \mathrm{~nm}$, o qual pode ser substituído por um outro, sensivel no vermelho até aos $900 \mathrm{~nm}$.

Os espectrofotómetros mais dispendiosos são de feixe duplo, utilizam duas fontes de radiação (lâmpadas de tungsténio e de deutério), monocromador duplo, e detectores e circuitos eléctricos sofisticados, com excelentes razões sinal/ruído. Estes espectrofotómetros têm resoluções da ordem de $0.1 \mathrm{~nm}$ e permitem o traçado de espectros de absorção na gama de $180 \mathrm{~nm}$ a $900 \mathrm{~nm}$ (0 uso de detectores de sulfito de chumbo permite estender a gama de comprimentos de onda ao infravermelho). A componente de luz parasita é geralmente inferior a $0.001 \%$ da intensidade do feixe incidente, em toda a gama de comprimentos de onda.

Em meados dos anos 70 , foram introduzidos os espectrofotómetros com detectores baseados em baterias de fotodíodos.

Neste tipo de espectrofotómetros a radiação dispersa é analisada por uma nbateria de fotodiódos sensiveis a gamas estreitas de energia, estando-se, assim, o varrimento mecânico do espectro. Estes espectrofotómetros tornaram-se muito populares, por permitirem a aquisição
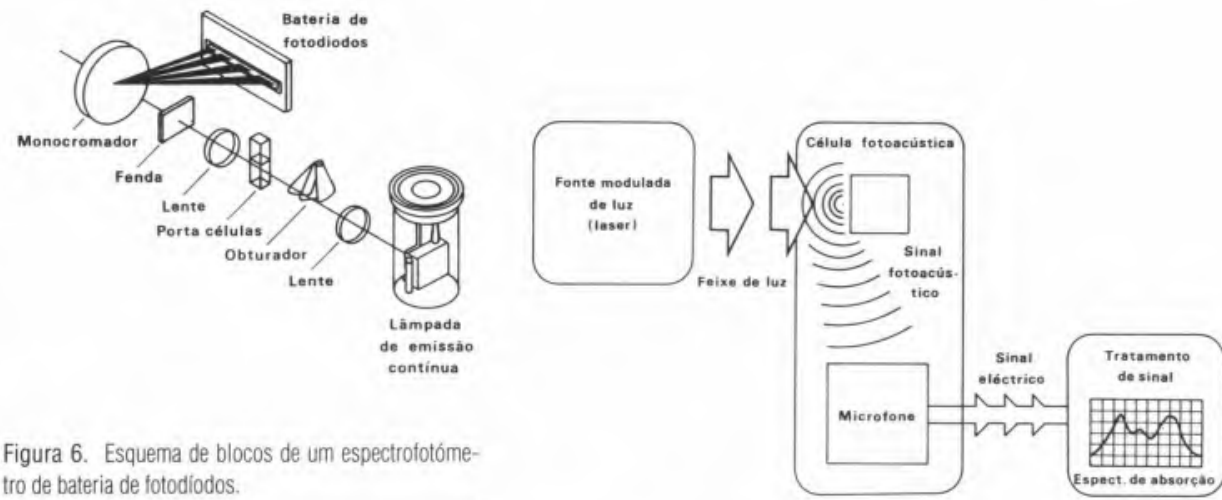

Figura 6. Esquema de blocos de um espectrofotómetro de bateria de fotodíodos.

de um espectro (200nm a $800 \mathrm{~nm}$ ) em menos de $0.1 \mathrm{~s}$. A sua principal limitação reside na resolução espectral que, tipicamente, é da ordem de $2 \mathrm{~nm}$.

\subsection{Espectrofotómetros fotoacústicos}

A determinação de espectros de amostras sólidas e soluções turvas ${ }^{3}$ por métodos convencionais é difícil, devido à interferência da luz dispersa e reflectida. $\mathrm{Na}$ espectroscopia fotoacústica são detectados sinais fotoacústicos gerados pela espécie absorvente, quando dissipa a energia de excitação sob a forma de calor. A dissipação de calor provém dos processos de desactivação não radiativos, que envolvem a conversão da energia electrónica da espécie inicialmente excitada em energia translacional e rotovibracional das moléculas vizinhas. A expansão do meio, devida ao aumento da temperatura, gera um sinal fotoacústico, desde que o feixe de excitação seja modulado em frequência da região das ondas acústicas.

Na figura 7 representa-se 0 diagrama de blocos de um espectrofotómetro fotoacústico, composto por um feixe de luz modulada, uma célula fotoacústica onde são geradas as ondas sonoras e 0 detector (um simples microfone) que produz um sinal eléctrico, que é depois amplificado e registado.

A intensidade do sinal fotoacústico, em condições experimentais adequadas, depende linearmente da densidade óptica, $\alpha=\varepsilon c$, obtendo-se directamente 0 espectro de absorção ao fazer 0 varrimento dos comprimentos de onda de excitação. 0 sinal fotoacústico é gerado unicamente pelas espécies que absorvem a radiação de excitação, pelo que não é afectado pela luz dispersa e reflectida.
Figura 7. Esquema de blocos de um espectrofotómetrofotoacústico.

\subsection{Limitações instrumentais}

A radiação electromagnética usada nos espectrómetros e espectrofotómetros é policromática, pois provém da selecç̧ão por filtros ou monocromador da radiação emitida por uma lâmpada de espectro contínuo. Estes seleccionam uma banda de radiação mais ou menos estreita em energias, deixando ainda passar luz parasita com energia muito diferente da radiação seleccionada.

\subsubsection{Importância da monocromaticidade}

0 uso de radiação policromática provoca desvios à lei de Beer, pois o coeficiente de absorção molar, $\varepsilon$, depende do comprimento de onda da radiação. Na figura 8 apresentam-se três situações para luz composta de 2 comprimentos de onda, verificando-se um aumento do desvio para grandes diferenças entre os valores do coeficiente de absorção molar.

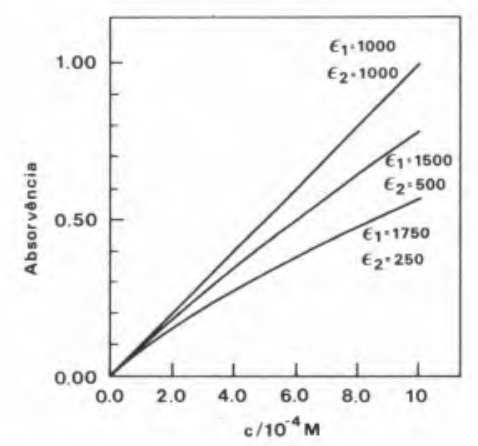

Figura 8. Efeito do uso de radiação policromática (constituida por dois comprimentos de onda) na variação da absorvência com a concentração. 


\section{técnicas experimentais}

De modo a diminuir a influência da policromaticidade na determinação de absorvências, estas devem, sempre que possivel, ser efectuadas na região da banda de absorção onde as variações com o comprimento de onda sejam mínimas. Na figura 9 observa-se que, no caso de uma banda de absorção larga, as absorvências no máximo de absorção (região $A$ ) seguem a lei de Beer, enquanto na zona lateral da banda (região B) os desvios são significativos.

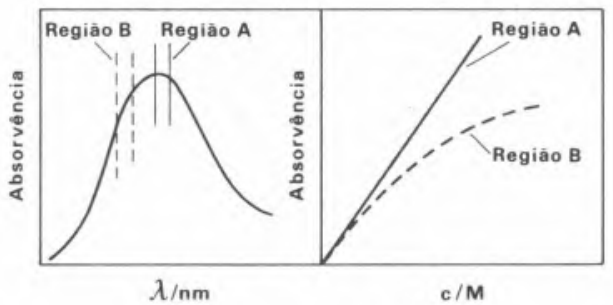

Figura 9. Efeito do uso de radiação policromática da região do máximo da banda de absorção (região A) e da zona lateral (região B) na variação da absorvência com a concentração.

Este problema é importante quando se usam fotómetros (espectrofotómetros) baratos, que não permitem a selecção de uma banda estreita de comprimentos de onda. Por outro lado, a monocromaticidade do feixe de luz, determinada pelas fendas de entrada e saída do monocromador, limita também a resolução do espectro de absorção. A figura 10 ilustra a perda de resolução de um espectro com 0 aumento da largura de banda do monocromador.
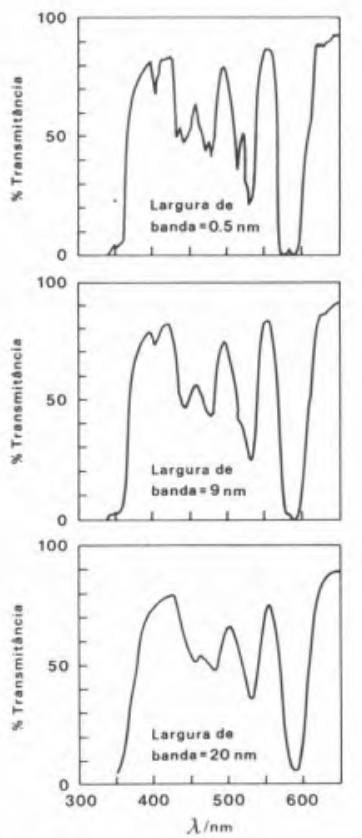

Figura 10. Efeito da largura de banda do monocromador na resolução do espectro de absorçẫo.
Para resolver uma banda de absorção é necessário que a largura de banda do monocromador seja inferior a $10 \%$ da largura da banda de absorção. Esta condição pode ser impraticável, pois a diminuição da largura das fendas do monocromador reduz a intensidade do feixe, 0 que provoca a diminuição da razão sinal/ruído.

\subsubsection{Luz parasita}

Na presença de luz parasita (luz de comprimento de onda diferente do seleccionado), a absorvência, Ap, é dada por

$$
A_{p}=\log \frac{I_{0}+I_{p}}{I+I_{p}}
$$

onde $I_{p}$ é a intensidade de luz parasita. Como a intensidade do feixe transmitido é inferior à do feixe incidente $\left(|<|_{0}\right) \mathrm{e}$ diminui com a concentração, a componente de luz parasita provoca desvios negativos à lei de Beer (fig. 11).

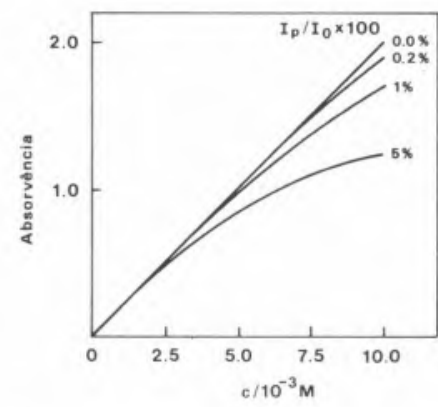

Figura 11. Efeito da luz parasita $\left(I_{p}\right)$ na variaçāo da absorvência com a concentração.

\section{DESENVOLVIMENTOS PRESENTES E FUTUROS}

0 desenvolvimento da espectroscopia de absorção UV-Vis está, em grande medida, associado às suas aplicações analíticas. Substâncias muito variadas, que vão desde os metais aos fármacos, são doseadas por absorção UV-Vis. Verificou-se nos últimos anos um aumento do interesse em processos de doseamento de substâncias orgânicas, em especial as de interesse biológico. A par do desenvolvimento de novos métodos de doseamento, também o tratamento de dados foi significativamente melhorado. Merecem especial referência os métodos de ajuste, em que são determinadas simultaneamente diferentes substâncias, usando absorvências a vários comprimentos de onda. Neste tipo de análise é, em geral, incorporada a informação das derivadas de várias ordens do espectro de absorção, que permitem uma melhor selectividade [2]. Estes métodos, que também possibilitam aumentar a sensibilidade das determinações, só se tornaram práticos com 0 advento dos espectrofotómetros de bateria de díodos, e com a vulgarização e expansão dos meios de cálculo.

\section{BIBLIOGRAFIA}

1. D. A. Skoog, D. W. West, F. J. Holler, Fundamentals of Analytical Chemistry, $6^{\text {th }}$ ed. Saunders College Publishing: New York, 1992.

2. L. G. Hargis, J. Howell, Anal. Chem. 64 (1992) 66 R.

3. a) F. C. Strong. Anal. Chem. 24 (1952) 338. b) M. N. Berberan-Santos, J. Chem. Educ. 67 (1990) 757.

4. a) R. C. Denney, R. Sinclair, Visible and Ultraviolet Spectroscopy, John Wiley\& Sons: New York, 1988. b) H. H. Jaffé, M. Orchin, Theory and Applications of Ultraviolet Spectroscopy, Wiley: New York, 1962. c) C. N. R. Rao, UltraViolet and Visible Spectroscopy: Chemical Applications, 3rd ed., Butter worths: London, 1975.

5. H. H. Jaffé, D. L. Beveridge, M. Orchin, J. Chem Educ. 44 (1967) 383.

6. M. L. S. S. Gonçalves, Métodos Instrumentais para Análise de Soluçōes, $2^{\mathfrak{a}}$ edição, Fundaçāo Calouste Gulbenkian: Lisboa, 1990.

7. F. A. Cotton, A. Wilkinson, P. L. Gauss, Basic Inorganic Chemistry, $2^{\text {nd }}$ ed., Wiley: New York, 1987.

8. a) A. Rosencwaig, Anal. Chem. 47 (1975) 592 A b) J. F. McClelland, Anal. Chem. 55 (1983) 89A.

\section{NOTAS}

${ }^{1} \mathrm{~A}$ intensidade fotónica do feixe de radiação é proporcional ao número de fotōes por $\mathrm{m}^{2} \mathrm{e}$ por $\mathrm{s}$, vindo expressa em einstein $\mathrm{m}^{-2} \mathrm{~s}^{-1} .0$ einstein representa uma mole de fotões.

${ }^{2}$ As unidades destas grandezas seguem a tradição enraizada na comunidade cientifica, que é contrária às recomendações da IUPAC. No sistema de unidades SI recomendado pela IUPAC, o coeficiente de absorção molar vem expresso $\mathrm{em} \mathrm{m}^{2} \mathrm{~mol}^{-1}$, a concentração $\mathrm{em} \mathrm{mol} \mathrm{m} \mathrm{m}^{-3} \mathrm{e} o$ percurso óptico em $\mathrm{m}$.

${ }^{3} 0$ s espectros destas substâncias são geralmente obtidos a partir da reflectância da amostra.

*Centro de Química-Física Molecular, Instituto Superior Técnico 1096 Lisboa Codex 


\section{ELECTROFORESE CAPILAR WATERS SOLUÇÕES DE VANGUARDA NAS ANÁLISES IÓNICAS}

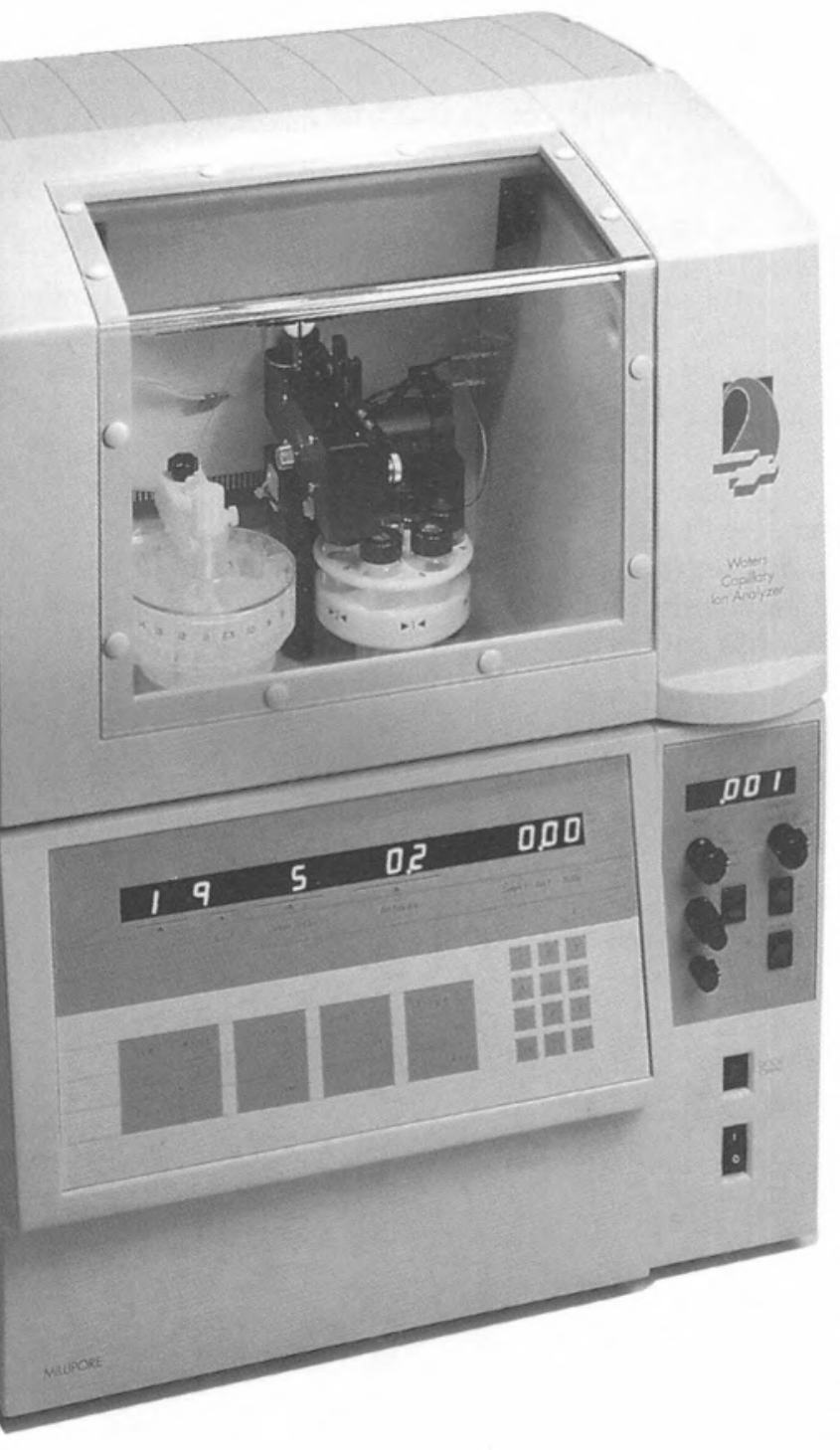

A MILLIPORE CORPORATION, fabricante de produtos e instrumentação Waters para as ciências de separação, dispõe também de um sistema de ELECTROFORESE CAPILAR-CIA (Capillary Ion Analysis), com as mais elevadas performances na Análise lónica.

O sistema QUANTA 4000 oferece novas possibilidades nas análises de aniões, catiões e ácidos orgânicos, desde ppb a ppm em tempos de análise muito mais rápidos do que com outros métodos.

Este sistema consegue sensibilidades e reprodutibilidades nunca dantes atingidas permitindo ainda:

- Identificação de picos de um modo preciso e exacto

- Controlo da temperatura para resultados consistentes

- Análises a $185 \mathrm{~nm}$ para maiores sensibilidades

- Desenvolvimento de métodos de um modo rápido e automático.

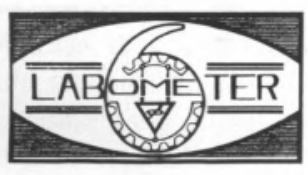

SOC. TÉC. DE EQUIP. DE LABORATÓRIO, LDA. Escritório - Rua Duque de Palmela, 30, 1. G Telefone 3537284 - 1200 LISBOA - PORTUGAL Armazém e Assist. - Rua S. Filipe Néri, $53,1 .{ }^{\circ} \mathrm{E}$ Telefone 685709 - 1200 LISBOA - PORTUGAL 